University of Nebraska - Lincoln

DigitalCommons@University of Nebraska - Lincoln

Faculty Publications in Computer \& Electronics Electrical \& Computer Engineering, Department Engineering (to 2015)

1996

\title{
Power Spectra of Signal Formats for DS-SS CDMA Wireless LANs
}

\author{
Beata J. Wysocki \\ University of Nebraska-Lincoln \\ Tadeusz Wysocki \\ University of Nebraska-Lincoln, wysocki@uow.edu.au
}

Follow this and additional works at: https://digitalcommons.unl.edu/computerelectronicfacpub

Part of the Computer Engineering Commons

Wysocki, Beata J. and Wysocki, Tadeusz, "Power Spectra of Signal Formats for DS-SS CDMA Wireless LANs" (1996). Faculty Publications in Computer \& Electronics Engineering (to 2015). 28.

https://digitalcommons.unl.edu/computerelectronicfacpub/28

This Article is brought to you for free and open access by the Electrical \& Computer Engineering, Department of at DigitalCommons@University of Nebraska - Lincoln. It has been accepted for inclusion in Faculty Publications in Computer \& Electronics Engineering (to 2015) by an authorized administrator of DigitalCommons@University of Nebraska - Lincoln. 


\section{Power Spectra of Signal Formats for DS-SS CDMA Wireless LANs Beata J WYSOCKI, Tadeusz A WYSOCKI \\ Cooperative Research Centre for Broadband Telecommunications and Networking Edith Cowan University, Joondalup Drive, Joondalup WA 6027, Australia \\ t.wysocki@cowan.edu.au}

\begin{abstract}
The paper deals with the spectral analysis of signal formats for DS-SS CDMA WLANs. The main emphasis is put on introduction of a quantitative measure which allows for comparison of different spreading codes and channel modulations from the viewpoint of a uniformity of an in-band power distribution. Such a measure is essential to compare different DS-SS CDMA systems performance in mitigating the effects of frequency selective fading.
\end{abstract}

\section{INTRODUCTION}

One of the major challenges faced by the telecommunication industry worldwide is development and commissioning of high capacity, wireless local area networks (WLANs). Current WLANs designed for high speed data transmission such as those considered by the IEEE 802.11 [1] and HYPERLAN [2] standards, mainly operate, or are going to operate, on industrial scientific medical (ISM) bands using either single carrier per channel frequency hopping spread spectrum (SCPC FH SS) or direct sequence spread spectrum (DS SS) schemes. For data rates of several Mbps, as required in ATM WLANs, a severe BER degradation is caused by the channel dispersion due to multipath propagation. Multipath propagation and the non-stationary nature of an indoor microwave channel cause frequency selective fading. Additionally, there are strong jammers [3] such as microwave ovens, door sensors, medical appliances and, the most critical, other users of the same WLAN system utilising the limited bandwidth of the ISM band.

The problem of frequency selective fading can be successfully resolved if frequency or space diversity are applied. The best results can be achieved if both techniques are used. One of the well known methods to achieve the frequency diversity is usage of DS SS. The DS-SS technique combined with a Code Division Multiple Access (CDMA) can be used to create several radio channels within the available ISM band shared among the users on a TDMA or CSMA basis.

In design of a DS-SS CDMA WLAN there is certainly a need, as always with bandlimited systems, to look into the spectral characteristics of signals to be transmitted. However, because DS-SS CDMA technique is supposed to be used not only to allow for creation of multiple radio channels but also to combat frequency selective fading, apart from usual bandwidth considerations, one must to consider a uniformity of signal power distribution within the pass-band. Therefore it is essential to establish a quantitative measure which allows to compare different spreading codes and channel modulations from the viewpoint of their in-band power distribution.

The measure introduced in the paper can be used together with the bandwidth occupied by the signal to compare the frequency diversity performance of different spreading codes combined with BPSK and QPSK modulations.

\section{DS-SS CDMA SIGNALS AND POSSIBLE SPREADING CODES}

For a conventional DS-SS CDMA system, the harmonic carrier $c(t)=A \cos \left(\omega_{0} t\right)$ is usually either BPSK or QPSK modulated, however, there is no restriction placed on the type of neither the waveform nor the modulation [6].

In the case of an angular modulation, the modulated signal, $s_{1}(t)$, is expressed as:

$$
s_{1}(t)=A \cos \left[\omega_{0} t+\phi_{1}(t)+\phi_{0}\right]
$$

where:

A - the amplitude,

$\omega_{0}=\frac{2 \pi}{T_{0}}-$ angular carrier frequency,

$T_{0}$ - period of the carrier,

$\phi_{1}(t)$ - the information carrying phase,

$\phi_{0} \quad$ - initial value of the phase.

Next the signal $s_{1}(t)$ is multiplied by the spreading signal $g_{1}(t)$ belonging to user 1 , and the resulting signal $g_{1}(t) s_{1}(t)$ is transmitted over the radio channel. Simultaneously, all other users 2 through $\mathrm{N}$ multiply their signals by their own code functions. The signal $R(t)$ intercepted in the receiver 
antenna, neglecting the different path losses is given by:

$$
\begin{aligned}
R(t)= & g_{1}\left(t-\tau_{1}\right) s_{1}\left(t-\tau_{1}\right) \\
& +g_{2}\left(t-\tau_{2}\right) s_{2}\left(t-\tau_{2}\right) \\
& +\ldots+g_{N}\left(t-\tau_{N}\right) s_{N}\left(t-\tau_{N}\right)
\end{aligned}
$$

where $\tau_{i} ; \mathrm{i}=1,2, \ldots, \mathrm{N}$ denote delays corresponding to different transmission paths associated with the user $\mathrm{i}$.

Assuming the receiver configured to receive messages from user 1 , which means the receiver being perfectly synchronised with the user 1 , the despread signal $r(t)$ is given by:

$$
\begin{aligned}
r(t) & =g_{1}{ }^{2}\left(t-\tau_{1}\right) s_{1}\left(t-\tau_{1}\right) \\
& +\ldots+g_{1}\left(t-\tau_{1}\right) g_{N}\left(t-\tau_{N}\right) s_{N}\left(t-\tau_{N}\right)
\end{aligned}
$$

where the term $g_{1}{ }^{2}\left(t-\tau_{1}\right) s_{1}\left(t-\tau_{1}\right)$ is the desired signal and the other terms $g_{1}\left(t-\tau_{1}\right) g_{i}\left(t-\tau_{N}\right) s_{i}\left(t-\tau_{N}\right) ; \quad(i \neq 1) \quad$ are the interfering signals responsible for the MAI. Because finally the signal is demodulated using the match fller or correlative detectors, with the stronger cross-correlation between the code $g_{1}\left(t-\tau_{1}\right)$ and other codes $g_{i}\left(t-\tau_{i}\right)$ the MA becomes morc severe.

For the shor signatures, as is the case of WLANS. where the spreading ratio can be lower than 20 . only a few of possible binary signatures of a given length $L \leq 20$ can be used as spreading codes. Therefore, the concept of a spreading code being a random scquence, as proposed in the Qualcomm CDMA system [8], cannot be used for WLANs. More feasible approach is to utilise either orthogonal Walsh-Rademacher functions for $L=8,16$, or Gold [7] codes for $L=7,15$, or optimise the dedicated code set for other lengths. In the paper we consider only Gold codes for $L=7$ and Walsh-Rademacher functions for $L=16$ together with BPSK and OPSK. The introduced spectral bumpiness measure and spectral estimation method can be, however, used for any code set and any channel modulation.

\section{POWER SPECTRUM ESTMATION}

The Power Spectral Density (PSD) of the resultant DS-SS CDMA signals have been estimated using the MATLAB Signal Processing Toolbox built in function 'psd' which utilises the Welch's PSD estimation method [9]. To get the reliable results, the PSD estimates have becn calculated for the sampled signals corresponding to random, binary sequences of
128 data bits with an accuracy of 16 samples per single chip interval. Later, as it is commonly applied, results have been normalised, with frequency normalised according to the formula:

$$
f_{\text {norm }}=T\left(f-f_{0}\right)
$$

where $T$ is the symbol duration (duration of a data bit for BPSK), and PSD in [dB] given by:

$$
\operatorname{PSD}\left(f_{n o r m}\right)=10 \cdot \log \left[\frac{p s d}{\left.p s d\right|_{f_{n o r m}}=0}\right]
$$

with $p s d$ being a raw estimate returned by MATLAB "psd" function.

The examples of PSD plots for BPSK and QPSK with a 16-bit Walsh-Rademacher spreading function are given in Figure 1 and 2, respectively. The similar plots, however, with a 7 -bit Gold signature are presented in Figure 3 and 4

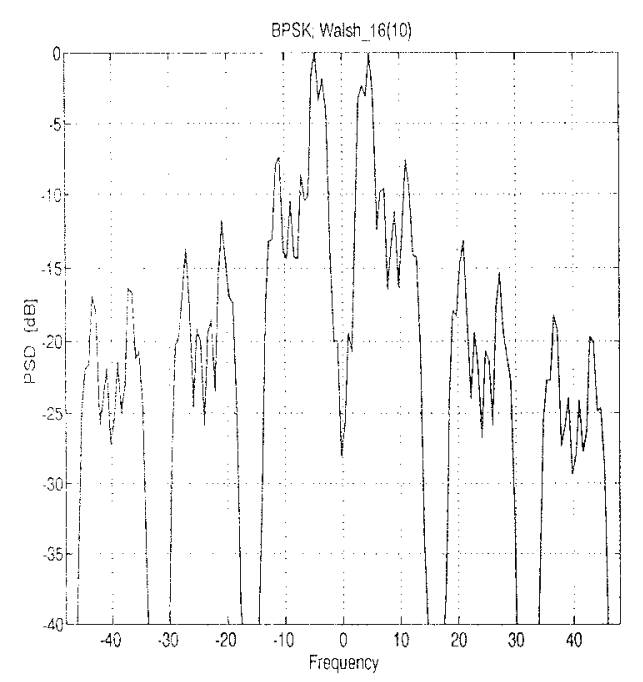

Figure 1: Example of PSD for a BPSK signal
with one of Walsh-Rademacher signatures.

\section{SPECTRAL BUMPINESS}

From the plots shown in the Fig. 1, 2, 3, and 4, it is visible, that apart from the bandwidth occupied by the certain amount of the signal power, it is really difficult to compare the plots. It is also clear, that the transmitted signals are not equally immune to the deep fades occurring at different frequencies. Since an indoor microwave channel is highly non-stationary, 


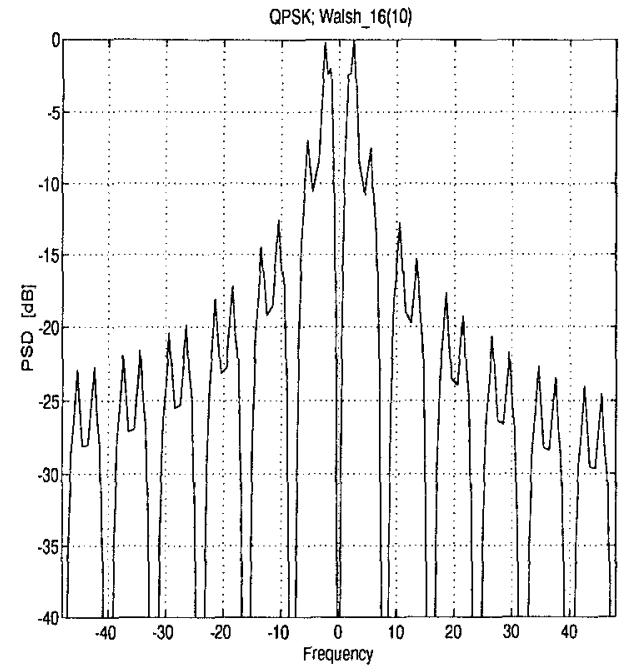

Figure 2: Example of PSD for a QPSK signal with one of Walsh-Rademacher signatures.

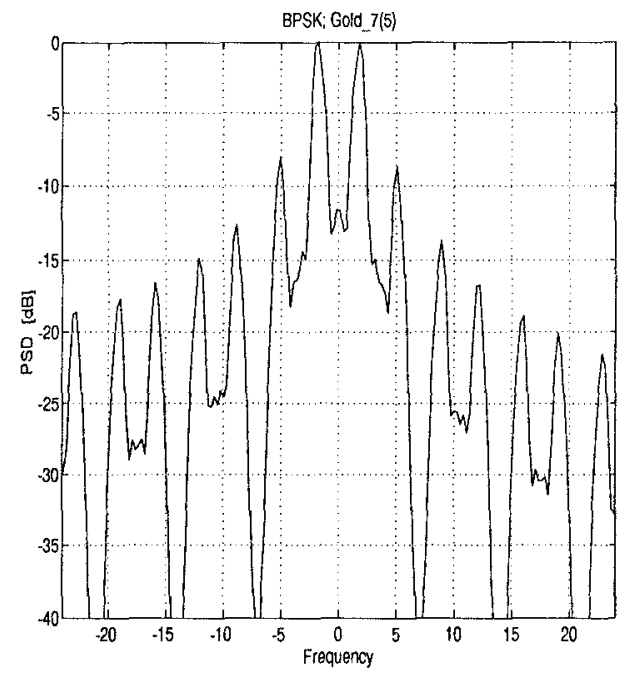

Figure 3: Example of PSD for a BPSK signal with the Gold codes signature "11-1-111-1".

it is desired to use the signals possessing uniform level of protection against such fades for all the bandwidth where the substantial percentage of the signal power is contained. In order to compare the different modulations and different spreading signatures from the view point of the uniformity of protection against frequency selective fading, we introduce the parameter $S B_{b}$, referred later as a spectral bumpiness, defined as:

$$
S B_{b}=\frac{\sigma_{b}}{\bar{S}_{b}},
$$

where:

$\bar{S}_{b}, \sigma_{b}$ - are, respectively, an average and a standard deviation of the $p s d$ truncated to the interval containing $b$ percent of the signal power.

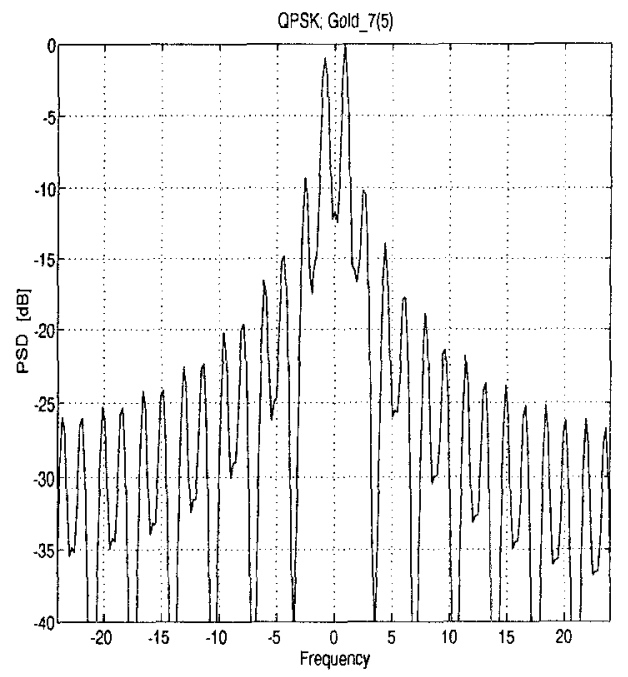

Figure 4: Example of PSD for a QPSK signal
with the Gold codes signature "11-1-111-1".

Because the PSD usually drops significantly in magnitude at the frequencies close to the limits of $99 \%$ or $-20 \mathrm{~dB}$ bandwidth, it is necessary to take the value of $b$ not too large, usually about $80-90 \%$, to avoid the value of $S B_{b}$ being influenced by those drops.

As an example, in the Table 1 the values of $S B_{90}$ are given for BPSK modulation and all 16-bits Walsh-Rademacher functions, and for the comparison, in Table 2 the equivalent results for 7-bits Gold codes are presented. It is clearly visible that the values of the spectral bumpiness $S B_{90}$ for the first two Walsh-Rademacher functions are much lower than for any other tested signatures, either Walsh-Rademacher or Gold codes. It does not imply, however, that the frequency diversity obtained by the use of these two signatures is good, because the spreading ratios associated with the use of them are very low, and equal to 1 , i.e. no spreading at all, and 2 , respectively. In contrary, the spreading ratio associated with the use of the 16th Walsh-Rademacher function is very high, but this is foreshadowed by the very high value of the corresponding parameter $S B_{90}$. 
Table 1: Spectral bumpiness for BPSK and 16-bit Walsh-Rademacher signatures.

\begin{tabular}{|c|c|}
\hline Signature & $S B_{90}$ \\
\hline 1111111111111111 & 0.11 \\
\hline$-1-1-1-1-1-1-1-111111111111$ & 0.20 \\
\hline$-1-1-1-11111111111-1-1-1-1$ & 0.50 \\
\hline $11111-1-1-1-1111111-1-1-1-1$ & 0.73 \\
\hline $11-1-1-1-11111111-1-1-1-111$ & 1.17 \\
\hline$-1-111111-1-1111-1-1-1-111$ & 0.81 \\
\hline$-1-111-1-111111-1-1111-1-1$ & 0.88 \\
\hline $11-1-1111-1-1111-1-1111-1-1$ & 1.39 \\
\hline 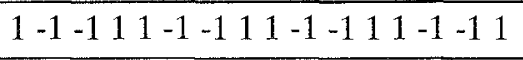 & 1.46 \\
\hline$-1111-1-1111-111-1-1111-1-11$ & 1.21 \\
\hline$-111-111-1-1111-1-111-1111-1$ & 1.10 \\
\hline 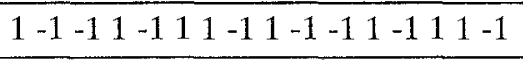 & 1.42 \\
\hline 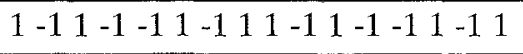 & 1.41 \\
\hline$-11-1111-11-111-11-1-111-11$ & 1.10 \\
\hline$-11-111-111-1111-111-11-11-1$ & 1.34 \\
\hline 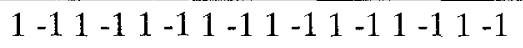 & 2.38 \\
\hline
\end{tabular}

Table 2: Spectral bumpiness for BPSK and 7-bits Gold code signatures.

\begin{tabular}{|c|c|}
\hline Signature & $S B_{90}$ \\
\hline $1-11111-1-1$ & 0.73 \\
\hline $11-11-1-11$ & 1.02 \\
\hline$-1111-11-11$ & 0.74 \\
\hline$-11-1-1 \quad 1-1-1-1$ & 0.65 \\
\hline $11-1-111-1$ & 1.02 \\
\hline $1-1-1-1-1-11$ & 0.83 \\
\hline $\begin{array}{lllllll}-1 & -1 & 1 & -1 & -1 & 1 & -1\end{array}$ & 1.10 \\
\hline $1111-111$ & 0.63 \\
\hline$-1-1-11111$ & 0.51 \\
\hline
\end{tabular}

\section{CONCLUSION}

In the paper we have introduced the spectral bumpiness parameter which can be used in assessing an immunity of a Spread Spectrum signal for frequency selective fading. This measure can be of a particular use in design of WLANs and other SS systems characterised by a low spreading ratio. It is, however, necessary to emphasise that the spectral bumpiness cannot be used as a sole parameter to determine an efficiency of a frequency diversity obtained by the use of a particular scheme. It is always necessary to consider the spreading ratio as well.

\section{REFERENCES}

[1] IEEE Draft Standard P802.11/D2.1-95/12, LAN Medium Access Control (MAC) and Physical Layer (PHY) Specification,"IEEE Publications, Rev. D2.1, December 1995.

[2] ETSI Technical Report, "Radio Equipment and Systems (RES); High Performance Radio Local Area Network (HIPERLAN) Services and facilities", DTR/RES-1003, Feb. 1993.

[3] E.Walker, J.Hislop, T.Wysocki; "Noise Measurements in a $2.3-2.5 \mathrm{GHz}$ Band", paper submitted to: 4 th UK/Australian International Symposium on DSP for Communication Systems".

[4] T.Wysocki, K.T.Tan; "Simulation modelling of the effects of ISI performance of DS-CDMA codes for a Wireless LAN", Proc. of 1996 European Simulation Multiconference (ESM'96), Budapest, 2-6 June 1996.

[5] A. Duel-Hallen, J. Holtzman, Z.Zvonar; “ Multiuser Detection for CDMA Systems", IEEE Personal Communications, April 1995.

[6] B.Sklar; "Digital Communications; Fundamentals and Applications", Prentice Hall, Englewood Cliffs, New Jersey 07632, 1988.

[7] J.G.Proakis; "Digital Communications", 3rd ed., McGraw-Hill International, 1995.

[8] Anonymous; "Wideband Spread Spectrum Digital Cellular System Dual-Mode Mobile Station-Base Station Compatibility Standard", Standard Specification Proposal, QUALCOMM Inc., USA, May 1993.

[9] A.V. Oppenheim, R.W. Shafer; "Discrete-Time Signal Processing", pp. 311-312, Englewood Cliffs, NJ, Prentice-Hall, 1989. 